\title{
Violência epistêmica e a invenção do outro na narrativa \\ "O Pajé de Cristo", de Homer Dowdy
}

\author{
Epistemic violence and the invention of others in the \\ narrative "Christ's Witchdoctor" by Homer Dowdy
}

\author{
Raimundo Nonato de Pádua Câncio ${ }^{1}$ \\ Sônia Maria da Silva Araújo²
}

DOI: http://dx.doi.org/10.20435/tellus.v18i37.516

\begin{abstract}
Resumo: O pensamento materializado na forma de escritos é um importante recurso para disseminação de valores, conhecimentos e ideologias. A obra "O Pajé de Cristo", de Homer Dowdy, narra o processo de conversão dos povos indígenas Wai-wai ao cristianismo evangélico pelos missionários norte-americanos, o que se dá por meio da descrição de práticas educativas de catequização, fundamentadas na lógica da dominação e da superioridade epistêmica. O principal objetivo deste estudo é identificar as estratégias persuasivas utilizadas pelo autor-narrador para convencer o leitor de que o processo de conversão dos povos Wai-wai ao cristianismo evangélico foi necessário, mesmo num contexto em que conhecimentos e valores se explicam e se confrontam. Como referência, apresentamos algumas aproximações entre a corrente teórica Pós-Colonial e a perspectiva Decolonial, no que toca à crítica epistemológica, sobretudo para questionar o discurso imperialista norte-americano, engendrado pelos missionários evangélicos. O resultado deste estudo tem sido a necessidade de reinterpretação e de reescrita das narrativas sobre os povos indígenas da Amazônia como resposta ao colonizador.
\end{abstract}

Palavras-chave: violência epistêmica; práticas educativas; pós-colonialismo; decolonialidade.

\begin{abstract}
The thought materialized in the form of writings is an important resource for the dissemination of values, knowledge and ideologies. Homer Dowdy's "Christ's Whitchdoctor" tells the story of the conversion of the Wai-wai indigenous peoples to evangelical Christianism by American missionaries. This is done through a description of educational practices based on logic domination and epistemic superiority. The main objective of this study is to identify the persuasive strategies used by the author-narrator to convince the reader that
\end{abstract}

${ }^{1}$ Universidade Federal do Tocantins (UFT), Tocantinópolis, Tocantins, Brasil.

${ }^{2}$ Universidade Federal do Pará (UFPA), Belém, Pará, Brasil.

Tellus, Campo Grande, MS, ano 18, n. 37, p. 39-57, set./dez. 2018 
the process of conversion of the Wai-wai people to evangelical Christianism was necessary, even in a context in which knowledge and values are explained and confronted. As a reference, we present some approximations between the Post-colonial theoretical current and the Decolonial perspective, with regard to epistemological criticism, especially to question the North American imperialist discourse engendered by evangelical missionaries. The result of this study has been the need for reinterpretation and rewriting of the narratives about the indigenous peoples of the Amazonia as a response to the colonizer.

Keywords: epistemic violence; educational practices; post-colonialism; decoloniality.

\section{INTRODUÇÃO}

A realidade latino-americana e o contexto amazônico são marcados pelas resistências ao colonialismo ${ }^{3}$ e às formas de colonialidade ${ }^{4}$ produzidas pelos agentes do poder capitalista. Essas formas de colonialidade, materializadas em documentos escritos, são importantes recursos para disseminação e afirmação de valores, conhecimentos e ideologias. Portanto o estudo dessas narrativas não pode estar desvinculado do contexto histórico e político-social em que foram produzidas, pois, no mundo colonial, como testemunhou Las Casas (2008), a efetivação de uma epistemologia da força, exterminou, silenciou experiências e saberes das populações não europeias e produziu tanto o genocídio quanto o epistemicídio, configurando, assim, o que designamos de violência epistêmica e injustiça cognitiva.

Ao mesmo tempo em que as marcas de opressão estão impregnadas nos discursos, as marcas da resistência também sobressaem, ainda que sejam ofuscadas pelas estratégias persuasivas e intenções que norteiam a maneira de significar o "outro". Como exemplo disso, a obra "O Pajé de Cristo", de Homer Dowdy, é considerada um "romance" que apresenta o processo de conversão dos povos indígenas Wai-wai ao cristianismo evangélico, o que ocorreu na região

\footnotetext{
3 Trata-se de uma estrutura de dominação e de exploração que se manifesta no controle da autoridade política, dos recursos de produção e do trabalho de uma população determinada (QUIJANO, 2007).

${ }^{4} \mathrm{Na}$ modernidade, o colonialismo está relacionado ao que se convencionou chamar de colonialidade. A colonialidade se manifesta, principalmente, a partir da ideia de raça, ao instituir um conjunto de relações de poder que hierarquizam lugares e suas gentes, classificando-os de acordo com um suposto grau de evolução e desenvolvimento societário (MIGNOLO, 2007).
} 
amazônica e foi engendrado, inicialmente, pelos irmãos Roberto, Nilo e Rader Hawkins, missionários norte-americanos. Essa obra é permeada de descrições de práticas educativas de catequização, fundamentadas na lógica da moral cristã, na superioridade intelectual e na dominação epistêmica.

Nessa perspectiva, o principal objetivo deste estudo é identificar as estratégias persuasivas utilizadas pelo autor-narrador para convencer o leitor de que o processo de conversão dos povos Wai-wai ao cristianismo evangélico foi necessário, mesmo num contexto em que conhecimentos e valores se explicam e se confrontam. Para tanto, discutem-se questões sobre as estratégias colonizadoras, o papel do colonizador na formação educacional do colonizado através da língua e do fundamentalismo religioso, a degradação de qualquer expressão cultural indígena e as práticas dissidentes dos povos Wai-wai.

Como referência, apresentam-se algumas aproximações entre a corrente teórica Pós-Colonial e a perspectiva Decolonial, no que toca à crítica epistemológica, sobretudo para questionar o discurso imperialista norte-americano e o pensamento colonialista moderno, engendrado pelos missionários evangélicos, quando do processo conversão dos povos Wai-wai ao cristianismo evangélico. Em termos de perspectiva metodológica, trata-se de um estudo de natureza teórica, uma vez que está voltado para o exame crítico dos quadros de referência de uma obra, as suas condições explicativas da realidade (DEMO, 2000, p. 20), tendo em vista, em termos imediatos, problematizar fundamentos teóricos.

\section{A INVENÇÃO DO OUTRO E AS CONDIÇÕES DE PRODUÇÃO DO CONHECIMENTO}

Como forma de situar contextualmente os diversos saberes e criticar as pretensões universalistas do pensamento ocidental hegemônico, Mignolo (2003) aponta para uma geopolítica do conhecimento, fundamentado na ideia de que há uma relação direta entre o lugar de enunciação do conhecimento e suas formas de validação, ou seja, o lugar de fala determina o objeto e o conteúdo do conhecimento, bem como o seu valor de verdade.

Para Mignolo (2003), as teorias pós-coloniais estão construindo um novo conceito de razão como resposta à superioridade da racionalidade moderna. Nesse sentido, as histórias fronteiriças apresentam-se como narrativas capazes 
de acomodar os sistemas de conhecimento e as práticas de vida dos povos que têm sido subjugados pelo paradigma eurocêntrico da modernidade, trazendo consigo uma nova dimensão epistemológica.

Trata-se daquilo que surge como resposta à necessidade de repensar e reconceitualizar as "histórias narradas e a conceitualização apresentada para dividir o mundo entre regiões e povos cristão e pagãos, civilizados e bárbaros, modernos e pré-modernos e desenvolvidos e subdesenvolvidos, todos eles projetos globais mapeando a diferença colonial" (MIGNOLO, 2003, p. 143). Nesse paradigma epistemológico, o lugar de produção do saber se torna oculto, pois, ao universalizar uma forma de conhecimento, faz desaparecer o lugar de enunciação do outro. Foi dessa forma descontextualizada que as ideias, os conceitos e as perspectivas ocidentais foram introduzidos nas mais diversas culturas.

Nessa direção, as teorias pós-coloniais se disseminaram no sentido comum de questionar as narrativas imperialistas da modernidade e, a partir de suas margens, revelar o subalterno como parte constitutiva dessa experiência histórica. Para tais teorias, a narrativa hegemônica da modernidade conferiu às nações imperialistas um locus privilegiado de enunciação, que, mesmo após o fim do período colonial, continuou a favorecer aspectos da ideologia imperial, com fundamento no modelo civilizacional europeu, naturalizando-se em todas as sociedades como o percurso universal do desenvolvimento.

Nesse processo, as línguas faladas pelos povos colonizados não eram consideradas aptas para o pensamento racional e "revelavam" a inferioridade dos seres humanos que as falavam. Os sujeitos então se dispunham a "aceitar" a humilhação de serem considerados inferiores ou decidiam assimilar-se. E assimilar-se significava aceitar sua condição de inferioridade e resignar-se a um jogo que não era seu, mas que lhe foi imposto (MIGNOLO, 2017, p. 21). Em contraposição, sempre houve tentativas de desprendimento dessas condições, o que tornava os sujeitos epistemologicamente desobedientes (desobediência epistêmica), localizando-os num pensamento fronteiriço que confrontava os projetos globais. Portanto, somente pela desobediência epistêmica que se fazia saber e conhecer.

Para se fazer conhecer e saber, entretanto, um enunciado necessita de um (agente) enunciador e uma instituição. Mas, para impor um padrão no imaginá- 
rio coletivo, é necessário estar em posição de gerenciar o discurso pelo qual se nomeia, se descreve uma entidade e se faz crer que ela existe. O conhecimento, portanto, está ancorado em enunciados que configuram projetos com orientação histórica, econômica e política. E o que desvelou a colonialidade foi "a dimensão imperial do conhecimento ocidental que foi construída, transformada e disseminada durante os últimos 500 anos" (MIGNOLO, 2017, p. 24).

A exemplo disso, os grandes silêncios e hiatos dos povos indígenas podem ser evidenciados no pensamento colonialista moderno, veiculado nas narrativas imperialistas norte-americanas, dignas de serem apreciadas no contexto pós-colonial brasileiro. E essa negação de uma parte da humanidade é sacrificial, na medida em que constitui a condição para que a outra parte da humanidade se afirme como universal (SANTOS, 2007, p. 76).

Conforme Santos (2007, p. 74),

A modernidade ocidental, em vez de significar o abandono do estado de natureza e a passagem à sociedade civil, significa a coexistência de sociedade civil e estado de natureza separados por uma linha abissal com base na qual o olhar hegemônico, localizado na sociedade civil, deixa de ver e declara efetivamente como não-existente o estado de natureza.

Com relação às populações indígenas, para declará-las como não existente, muitas estratégias foram utilizadas. Entre elas, podemos citar a violência exercida pela proibição do uso das línguas próprias em espaços públicos, a adoção forçada de nomes cristãos, a conversão e a destruição de símbolos e lugares de culto, dentre outras. No que se refere à episteme, tem ocorrido a destruição de sistemas inteiros de tradições transeculares de conhecimentos, o que também impediu a socialização e a divulgação de modos diversos de pensar o mundo. Considerando-se tais questões, parte-se da premissa de que as formas de dominação e as relações de poder não poderiam ser pensadas nem rearticuladas sem se pensar os níveis de produção do conhecimento e os efeitos de verdade que os sustentam.

Para Mignolo (2017, p. 13), essa forma de "Colonialidade" equivale a uma "matriz ou padrão colonial de poder". Segundo o autor, trata-se de um complexo de relações que se esconde detrás da retórica da modernidade (o relato da salvação, progresso e felicidade) que justifica a violência da colonialidade. No 
campo da produção e divulgação do conhecimento científico, essa forma de colonialidade também está presente no modo historicista e etnográfico que prevalece no discurso da modernidade política, o que pode ser evidenciado nas narrativas sobre os povos indígenas da Amazônia. Trata-se do reconhecimento das distorções produzidas pelo imperialismo e ainda mantidas pelo sistema capitalista atual. E, nesse sentido, a crítica pós-colonialista é enfocada, no contexto atual, como uma abordagem alternativa para compreender o imperialismo e suas influências.

É importante observar que os argumentos pós-coloniais ${ }^{5}$ e mesmos os decoloniais já estavam presentes nas produções de intelectuais latino-americanos do século XIX, como aponta Luciana Ballestrin (2013). Todavia o que diferencia o pensamento anterior e o atual é o contexto em que foram elaborados e as possibilidades desses contextos. No âmbito da América Latina, os estudos decoloniais vêm se destacando recentemente e assumem uma perspectiva de crítica ao colonialismo, semelhante aos estudos pós-coloniais. Mas o seu ponto de referência se dá a partir da América Latina. Trata-se, portanto, de uma epistemologia de fronteira que questiona a subalternização dos conhecimentos dos grupos oprimidos e propõe uma lógica de pensar diferente, que considere e inclua a densa trama histórica e simbólica que está implicada nos conhecimentos subalternos.

Com relação à produção do conhecimento sobre os povos indígenas no contexto da América Latina, o crescente poderio político dos Estados Unidos e sua capacidade de dominação influenciou e ainda influencia a produção de obras, muitas vezes utilizadas como "boas" referências, fazendo com que esses conhecimentos sejam legitimados em determinadas áreas, dada a falta de diálogo e confronto com outras epistemologias. Essa forma de invasão e de tentativa de sobreposição ao conhecimento do outro tem alimentado, em muitos casos, a negação, a representação desprestigiosa que tem colocado o indígena num grau de inferioridade, terreno simbólico atravessado por relações sociais desiguais.

\footnotetext{
${ }^{5}$ Os discursos críticos pós-coloniais exigem a desconstrução das metanarrativas do discurso coIonial, destacando os processos, as inter-relações e seus desdobramentos. Trata-se do desafio de reescrever a história, dar destaque às vozes silenciadas pelas ideologias que legitimaram o processo de colonização. Por sua vez, a crítica decolonial também implica disputas e lutas contínuas, mas o seu ponto de referência se dá a partir da América Latina.
} 
Essas representações desprestigiosas e relações sociais desiguais sempre estiveram presentes no discurso imperialista para justificar as ações missionárias na Amazônia. No que se refere à ação missionária norte-americana entre alguns povos indígenas dessa região, principalmente a dos missionários protestantes da Unenvangelized Fields Mission (UFM), Ferreira (2001, p. 72) comenta que, nos internatos, o ensino de português era imposto como forma de superar o uso das línguas nativas, sendo, muitas vezes, as crianças separadas das famílias, e investia-se na capacitação profissional dos indígenas como forma de produzir mão de obra barata para os não indígenas.

Com a extinção do Serviço de Proteção ao Índio (SPI), em 1967, e a criação da FUNAI, esta instituição passa então a adotar um novo discurso, fundamentado nos referenciais teórico-metodológicos de instituições como o Summer Institute of Linguistics (SIL). E a base e motivações do SIL eram de fundamento e ordem religiosa. Para justificar tal ação, sempre prevaleceu, nas narrativas produzidas pelas missões religiosas, a figura do indígena como um ser em degradação, com "relativa incapacidade" e necessidade de "tutela" pelos órgãos do Estado, como a igreja.

No entanto poucos estudos questionam as narrativas produzidas pelos missionários norte-americanos sobre o processo de conversão dos povos indígenas Wai-wai ao cristianismo evangélico. É preciso, portanto, indagar com quais sentidos circula e em que redes conceituais e institucionais somos levados a repensar e a problematizar as práticas de produção do conhecimento na atualidade sobre os povos indígenas da região amazônica. Tal questão leva a afirmar que a produção e a disseminação do texto escrito ainda funciona como um espaço privilegiado para alguns, ao mesmo tempo em que esse mesmo espaço colabora para reforçar e desigualdade e a subordinação de outros.

\section{O TRABALHO MISSIONÁRIO ENTRE OS WAI-WAI: "HÁ DOIS CAMINHOS, UM QUE LEVA A DEUS E OUTRO PARA LONGE DELE"}

O povo indígena "Waiwai", "Uaiuai" ou "Wai-wai", como conhecidos pela literatura etnológica, é uma designação genérica para um conjunto de grupos indígenas que se uniu em dado momento histórico e hoje habita uma extensa região que compreende o sul da Guiana (rio Essequibo), o leste do Estado de 
Roraima (rios Jatapu e Anauá) e o noroeste do Estado do Pará (rio Mapuera), na Amazônia setentrional, região onde a Serra Acaraí delimita a fronteira entre o Brasil e a Guiana. São falantes da Língua Wai-wai, além de outras línguas da família Karib.

O antropólogo dinamarquês Niels Fock (1963, p. 9), quem muito contribui para a compreensão da cultura Wai-wai antes da presença missionária entre eles, observou que "wai-wai" foi um termo criado pelos Wapixana para designar um povo indígena que possuía a pele mais clara. Do ponto de vista cultural, a formação Wai-wai deriva de uma mistura de grupos originais de indígenas Waiwai, Parukoto, Tarumã e Mawayana. Ao realizar pesquisa de campo nessa região nos anos de 1954 e 1955, Niels Fock já observava a dificuldade de determinar esse grupo devido à origem misturada. Todavia, segundo ele, do ponto de vista étnico, os Wai-wai são dominados pelos Parukoto, muito embora, do ponto de vista linguístico, pareçam independentes (FOCK, 1963, p. 9).

A partir da segunda metade o século XX, antropólogos e pesquisadores que visitaram a região do rio Mapuera-PA constataram e descreveram a grande transformação na cultura e na organização social desse povo indígena, levada a cabo pela Unevangelized Fields Mission, atualmente denominada Missão Evangélica da Amazônia (MEVA). Em 1949, os irmãos Rader, Neill e Robert Hawkins, missionários evangélicos norte-americanos da UFM, subiram o rio Essequibo, na Guiana, com ajuda de guias Wapixana. Neill permaneceu na Guiana, enquanto Rader e Robert continuaram a viagem com a ajuda de guias Wai-wai, até as aldeias no Mapuera, do lado brasileiro.

Os irmãos Hawkins são de uma família protestante em Dallas, no Texas. Segundo Oliveira (2010, p. 31), o Texas faz parte do chamado Bible Belt, uma região conservadora no Sul dos Estados Unidos onde predominam igrejas teologicamente orientadas a partir dos grandes reavivamentos do final do século XVIII e século XX e, em sua maioria, pelo fundamentalismo do início do século XX. Essa região está relacionada à "direita" protestante norte-americana, vertente usualmente identificada como evangelical, e se distingue da Main Line Protestant Church, adepta de uma teologia modernista ou liberal (OLIVEIRA, 2010).

A equipe dos Hawkins disseminou uma doença infecciosa entre os indígenas, que foram tratados com suprimentos de comprimidos e injeções. Essa visita deles à 
região dos Wai-wai durou três meses e foi uma sondagem para o estabelecimento de uma base missionária na Guiana, que ocorreu no ano seguinte. Também foi tempo suficiente para os missionários aprenderem um pouco da língua Wai-wai e começarem a pregar sobre um Deus amoroso, criador de todas as coisas, e sobre a existência de dois caminhos no mundo: um que leva a Deus e outro para longe dele (DOWDY, 1997, p. 89-90).

A presença dos estrangeiros "brancos" com suas mercadorias, escrita e histórias sobre Deus despertava a curiosidade dos Wai-wai, que vinham espontaneamente em busca de objetos para trocar e de remédios alopáticos. Houve, portanto, a intenção deliberada por parte da missão de agregar o maior número possível de indígenas para melhor evangelizá-los (HOWARD, 2001, p. 64). Mas, como a maior parte da população Wai-wai estava no Brasil e os missionários só tinham autorização para trabalhar na Guiana, a solução encontrada foi atrair os indígenas que habitavam em aldeias do lado brasileiro para Kanashen (Guiana). As principais estratégias para convencê-los a se estabelecerem nas imediações da missão foram a realização de viagens missionárias às aldeias vizinhas e a distribuição de remédios e presentes, tais como armas de fogo, miçangas, facas, espelhos etc. (FRIKEL, 1971, p. 20-31).

Em 1958, após as investidas catequéticas, os missionários batizaram os primeiros Wai-wai, e também comemoraram a construção de uma casa grande em Kanashen, destinada à realização de cultos religiosos (DOWDY, 1997, p. 237). As notícias sobre esse sucesso missionário logo se espalharam pela América do Norte, e, por volta de 1960, o jornalista Homer Dowdy visitou as aldeias na Guiana, onde realizou uma pesquisa para escrever um "romance" sobre a conversão dos Wai-wai ao cristianismo evangélico. Assim, o livro "O Pajé de Cristo" foi publicado em 1963, e seu fio condutor é a trajetória de Ewká, influente xamã e líder Waiwai, primeiro indígena a aceitar os ensinamentos dos missionários e o primeiro a se tornar pastor.

A conversão de Ewká, em 1954, influenciou a maioria dos Wai-wai, que também se converteram nos anos seguintes, daí o título significativo da obra, Christ's Witchdoctor: from savage sorcerer to jungle missionar, publicada nos Estados Unidos em 1963, e depois no Brasil, em 1997, traduzida para o português por Fausto Camargo César, sob a orientação da Missão Evangélica da Amazônia. Para 
escrever a obra, Homer Dowdy recolheu as histórias de vida de aproximadamente trinta indígenas, especialmente de Ewká, cujas memórias se basearam em grande parte nos acontecimentos narrados.

Além disso, o autor teve acesso a quase mil cartas e diários enviados pelos missionários às suas famílias ao longo de mais de dez anos. O livro é, portanto, uma propaganda missionária que apresenta a decisão de Ewká e, posteriormente, da grande maioria dos Wai-wai, como uma espécie de "saga" da vitória da fé sobre o medo, e da passagem de um passado de degradação e decadência a um presente de redenção e felicidade (DOWDY, 1997, p. 6).

Dessa forma, a linguagem, assim como a sua materialidade, é utilizada como interação e está ligada ao processo de formação do indivíduo, pois ele faz uso dela para expressar seus pensamentos e suas ideologias, construindo seus conhecimentos e valores. Contudo a linguagem também serve para comunicar e para não comunicar. É por isso que se diz que o papel mais proeminente da ideologia "é de cristalizar as cisões da sociedade, fazendo-as passar por naturais". Portanto "a ideologia não aclara, ou melhor, não diz a realidade, nem procura dizê-la, mascarando-a, homogeneizando os indivíduos aos clichês" (BRAGA, 1980, p. 51).

Considerando a visão de mundo de determinada classe, nesse caso a dos missionários evangélicos norte-americanos, e a dimensão de mascaramento ou falseamento da realidade dos povos indígenas Wai-wai, podemos dizer que, no discurso dos missionários, estão materializadas também as suas representações ideológicas, uma vez que "As ideias, as representações não existem fora dos quadros linguísticos [...] as formações ideológicas só ganham existência nas formações discursivas" (FIORIN, 1998, p. 34). Portanto, nesse caso, os discursos ideológicos dominantes não estão preocupados em considerar o contexto empírico, os conhecimentos e a realidade Wai-wai, mas alimentar a desigualdade entre as duas culturas, de modo a disseminar os valores, os conhecimentos e as ideologias produzidos pelos agentes do poder capitalista.

Nessa relação, os discursos produzidos por aqueles que detêm o poder capitalista, aproveitando-se de seu poder político, econômico e social, servem para impor a sua forma de pensar, seus valores e concepções sobre os que se encontram em condição de subordinação, fazendo com que estes sejam aceitos 
e naturalizados por todos. O que ocorre, nesse processo, é o massacre das realidades dos que se encontram em condição subalterna, o que se dá por meio da legitimação de práticas injustas, sob a argumentação de que toda situação social faz parte de um fenômeno natural, muito vezes justificado no poder divino.

Nesta perspectiva, é importante considerar que os valores sociais circulam nos diversos espaços por meio da linguagem, compreendendo a linguagem como um sistema simbólico produzido pelo ser humano. É necessário, portanto, que atentemos para o fato de que é por meio da linguagem que fazemos a mediação entre o sujeito e o "objeto" do conhecimento. Essa medição, na obra "O Pajé de Cristo", é conduzida por um discurso de ordem e de obediência absoluta às escrituras, o que se fez por meio de um jogo de forças, forjadas para legitimar o saber ocidental, esconder e rejeitar os conhecimentos indígenas.

\section{COLONIALIDADE DO SER E DO SABER: O LUGAR DE ENUNCIAÇÃO IMPERIALISTA NORTE-AMERICANA NA OBRA “O PAJÉ DE CRISTO”}

Não é novidade que os Estados Unidos sempre desejaram e criaram estratégias para obter o controle da região amazônica. O desejo de ingerência norte-americana sobre essa região já provocou, inclusive, várias tentativas de pressão para que se aceitasse o controle e a "proteção" da Amazônia brasileira, sob a alegação da incapacidade governamental de realizar essa tarefa com esforço próprio e da relevância da Floresta Amazônica para toda a humanidade. Nesse processo, sempre ficaram claras as ideologias imperialistas, principalmente nas investidas de missionários norte-americanos para pregar a moral cristã às populações indígenas amazônicas.

Pelo discurso religioso, os missionários buscaram seu domínio não só por meio da força ou do poder econômico, mas também exercendo uma liderança moral e intelectual e fazendo concessões, dentro de certos limites de interesses, levando, muitas vezes, os indivíduos a pensarem e verem o mundo a partir de um lugar que os colocava numa posição de subalternidade. Entre os mecanismos de silenciamento dos falantes indígenas apontados por Quijano (2005), destacamos o discurso político/científico utilizado pelos missionários norte-americanos para marcar a diferença entre eles e os Wai-wai como pertencentes a sociedades distintas hierarquicamente. 
Isso fica evidente em muitos trechos da obra de Homer Dowdy (1997) sobre a história de como Ewká, o líder religioso Wai-wai, e seu povo trocaram o medo pela fé em Cristo:

O povo parecia mesmo ter sido preparado por Deus para o trabalho que o Senhor estava prestes a realizar nele e por meio dele. Isto se tornava evidente, à medida que a degradação e decadência em sua vida pregressa se faziam conhecidas. Desde que nenhum homem sobrevive num vazio, os uaiuais foram sendo preparados para receber a mais profunda mudança que thes era oferecida. (DOWDY, 1997, p. 9).

É possível observar, nesse trecho da obra "O Pajé de Cristo", que, ao impessoalizar o discurso, Dowdy atribui ao Deus cristão o trabalho de conversão do povo Wai-wai ao credo evangélico. Trata-se de uma estratégia discursiva que busca "proteger a face" dos missionários diante desse projeto de invasão e da tentativa de sobreposição de um conhecimento ao outro. Sendo, portanto, "autorizados" pelo Deus cristão, que, nesse caso, age como "mediador", busca-se esquivar os missionários do contato direto com os indígenas, fundando um contato direto dos Wai-wai com Deus, já que o que está em questão é "o trabalho que o Senhor estava prestes a realizar nele e por meio dele".

O discurso político/científico é um recurso utilizado por Dowdy para mostrar que tal investida foi necessária porque os Wai-wai viviam na degradação, na decadência e num vazio. A ideia de vazio está relacionada à desqualificação dos conhecimentos indígenas diante dos conhecimentos dos norte-americanos, e é um recurso hierárquico de legitimação deste último saber. Entre os argumentos usados pelos missionários, havia aqueles que eram respaldados num padrão ideal de Ser, já que os indígenas eram concebidos como sujeitos corroídos pelos pecados, como expresso no seguinte trecho: "Há entre vocês alguns que gostariam de ser batizados. Vocês precisam abandonar seus pecados. Amem a Jesus, e não ao pecado. Não nos imitem; imitem a Deus. Não sejam preguiçosos em ouvir o Papel de Deus" (DOWDY, 1997, p. 239).

Essa forma de colonialidade põe em questão a qualidade do Ser, ou seja, os discursos que fundamentam a qualidade do Ser partem da ideia de que se trata de irmãos menores, próprios para cuidar, educar e evangelizar sob os preceitos de quem os julga, atitude que pode ser evidenciada na descrição de Homer Dowdy (1997, p. 168) na obra: 
Os uai-uais por si mesmos não podiam crer como Eucá cria; os uai-uais reagiam de modos muito diferentes ao novo ensino. Apenas uma prática da nova fé era compartilhada por quase todo povo: assistir regularmente às lições dominicais em Canaxen. Com graus diferentes de atenção e interesse os uai-uais iniciavam o cântico de hinos em sua própria língua. Alguns fechavam os olhos durante as orações- embora muitos se sentissem mais seguros conservá-los abertos quando o céu estava sendo invocado.

A ideia de cuidar, educar e evangelizar produziu a ideia de que os Wai-wai eram incapazes de pensar e de construir a própria história. Para que se constituíssem atores históricos, na percepção do autor-narrador, os Wai-wai deveriam permitir a submissão às perspectivas de vida, conhecimento, economia, religião, orientados pela moral e ética cristã norte-americana. Essa forma de colonialidade do Ser está muito relacionada à não existência e à desumanização (WALSH, 2007, p. 22).

É possível verificar na obra "O Pajé de Cristo" que as ideologias dos missionários norte-americanos, sustentadas pelo autor-narrador, estão carregadas de representações negativas do "outro", de estigmas e estereótipos, utilizados para justificar a ação missionária e a adaptação de uma nova conduta do indígena àquela realidade, a fim de formar e conformar consciências.

O fundamentalismo religioso norte-americano é uma das bases epistemológicas que sustentaram e tornaram possíveis os discursos e as condições necessárias para as práticas de catequização, classificação e exibição, decisivas, também, para uma percepção estereotipada dos povos indígenas Wai-wai, uma vez que a ética protestante era considerada superior à ética nativa pelos missionários, por conduzir ao progresso e à riqueza através do trabalho.

Portanto, segundo Oliveira (2010), uma das primeiras estratégias civilizadoras dos irmãos Hawkins era a produção de uma ética do trabalho entre os Wai-wai. Eles poderiam trabalhar para os missionários derrubando árvores, por exemplo, para construção da pista de pouso, fornecendo alimentos, fazendo serviços domésticos. Assim, eles teriam condições de adquirir os manufaturados que tanto desejavam, "já que seu hábito de queixar-se a fim de conseguir ferramentas dos brancos era considerado 'mendicância' pelos missionários" (OLIVEIRA, 2010, p. 36).

Ao relatar as estratégias discursivas para convencer e introduzir o cristianismo entre os Wai-wai, por meio de práticas educativas, Dowdy apresenta um 
mundo espiritual duplo em natureza (indígena-cristão), buscando introjetar no sujeito uma visão unilateral de contato com o Deus ocidental, colocando o indígena sujeito da história e da direção do seu processo de liberdade e de progresso. Não escolher Jesus significava continuar prisioneiro dos maus espíritos, como observado no trecho a seguir:

O Papel de Deus era como um novo feitiço [...] O ensino de Bam enfatizava os contrastes do mundo espiritual. - Jesus morreu e ressurgiu para destruir os maus espíritos- dizia. - Ele se sacrificou para libertar os cativos, prisioneiros dos maus espíritos. Jesus cortou as amarras e anulou o poder dos tabus. Se fez isso, como poderia Ele conviver ao lado dos maus espíritos dentro de você? Você precisa escolher entre Jesus ou os espíritos. Se Ele entrar, o maligno tem que sair. (DOWDY, 1997, p. 167).

Os fundamentos na moral cristã, enquanto instrumento do saber verdadeiro, se configura como uma forma de violência epistêmica e de injustiça cognitiva, características mais insidiosas do colonialismo na modernidade. A dominação epistêmica fica evidente em "O Pajé de Cristo" uma vez que o discurso imperialista busca distorcer a ancestralidade, confundir a história e os processos identitários próprios dos povos Wai-wai. Trata-se de uma tentativa de "remodelar" o universo de valores, rituais e comportamentos, segundo os parâmetros da religiosidade evangélico-fundamentalista.

Opondo-se à ideia de que não houve resistência aos discursos missionários, mesmo que, no contexto da aldeia, eles assumissem a função de intérpretes do texto sagrado, os Wai-wai também manifestavam resistência às estratégias dos missionários, conforme descrito por Dowdy:

Os uai-uais não encontravam dificuldades para compreender que Deus era um espírito. Os maus espíritos viviam entre o povo e os governavam; assim seria com o Espírito de Deus, se eles preferissem. De fato, Jesus tornou-se para todos apenas mais um espírito, acrescentado ao número ilimitado de espíritos que normalmente vivia ao redor deles. (DOWDY, 1997, p. 168).

Em muitas situações, os missionários não atingiam o objetivo desejado, no sentido de que o cristianismo dos missionários modificasse as práticas e representações Wai-wai, pois observavam que, entre eles, não havia aceitação dos ensinamentos "em seu estômago", ou seja, muitos Wai-wai resistiam às normas do cristianismo protestante, aos pensamentos, às percepções e ações. 
Em contraposição, eram utilizados argumentos de superioridade espiritual em favor da dominação política/econômica/cultural norte-americana, uma vez que, na obra, o autor busca justificar a manutenção dessa posição privilegiada, o que pode ser observado no prefácio da obra, assinado por uma das lideranças da MEVA, no ano em que a obra foi publicada: "Os leitores mais hão de notar que os argumentos que hoje se levantam contra a evangelização dos índios são os mesmos de quarenta anos passados, isto é, continuam ápodes e acéfalos- sem pé e sem cabeças" (DOWDY, 1997, p. 7).

A ideia da suposta falta de capacidade indígena para a aprendizagem era negada a cada investida dos missionários norte-americanos, em situações específicas. Dowdy (1997) descreve um momento da desconstrução dessa ideia no decurso do trabalho de alfabetização, pelos métodos de ensino da Língua Inglesa, para aprender a Língua Wai-wai na Aldeia Mapuera:

Eucá convivia muito com os missionários. Era ainda informante para o estudo da língua uai-uai e para a tradução das Escrituras. Os missionários eram uma espécie de Paulo, e ele, um Timóteo. Mas, freqüentando o lar dos missionários e vendo as ferramentas do homem branco, Eucá desenvolveu um apetite pelas coisas que possuíam [...] Eucá lia e tornava a ler até decorar as histórias e versículos que Bam e ele traduziam do papel de Deus [...] De sua escrivaninha expedia cartas aos uai-uais que sabiam ler, aos missionários em Canaxen, e até para Achi, que estava de férias nos Estados Unidos. (DOWDY, 1997, p. 171-2).

Com muita clareza, o autor-narrador descreve que Ewká era considerado um informante para que os missionários se apropriassem da Língua Wai-wai com a intenção de convertê-los ao cristianismo. Todavia essa resposta positiva também Ihe negava a percepção etnocêntrica da incapacidade intelectual indígena, uma vez que o xamã cada vez mais se aprofundava no conhecimento linguístico para a comunicação escrita na língua indígena, tendo como referência a Língua Inglesa.

Portanto a invenção do indígena como inferior, desprovido de capacidade intelectual, cujos argumentos eram fundamentados na lógica da moral cristã, na superioridade intelectual e na dominação epistêmica, era negada a cada investida. Isso fica evidente no trecho a seguir, quando o autor-narrador observa as regras e os rigorosos tabus impostos pelos Wai-wai e que serviam de proteção aos líderes religiosos na aldeia: 
A natureza generosa não Ihes proporcionava uma vida tranqüila. Em oposição ao que eles tinham de segurança, os maus espíritos estavam sempre tentando destruí-los. Regras e tabus rigorosos eram observados e a proteção dos feiticeiros era a única esperança de salvação. (DOWDY, 1997, p. 22).

Essa prática de imposição de uma lógica Wai-wai que subverte as práticas educativas de dominação, fundadas na ideia de superioridade epistêmica dos missionários norte-americanos, se configura como uma forma de desobediência para impor um poder, para se fazer saber e conhecer. O valor de verdade, assim como os recursos utilizados pelos missionários para disseminação e afirmação de seus valores, conhecimentos e ideologias entre os Wai-wai eram confrontados quando na relação direta com o lugar de enunciação indígena.

No entanto uma leitura menos atenta da obra "O Pajé de Cristo", dado o lugar privilegiado de enunciação imperialista norte-americano, mostra que o movimento dos Wai-wai em direção ao cristianismo segue um padrão convencional, comum às narrativas evangélicas, onde a ênfase é a redenção do indivíduo, já que este se reconhece como um ser inferior, tomado pelo pecado e que, por isso, necessita de salvação. De modo geral, a principal estratégia utilizada pelo autor-narrador, para desviar o olhar do leitor da lógica da dominação e da superioridade epistêmica norte-americana, é retratar um sujeito indígena que se autoimola para glorificação da missão social e espiritual de um povo que se julga superior.

\section{CONCLUSÃO}

Neste estudo, cujo objetivo foi identificar as estratégias persuasivas utilizadas pelo autor-narrador na obra "O Pajé de Cristo" para convencer o leitor de que o processo de conversão dos povos Wai-wai ao cristianismo evangélico foi necessário, foi possível verificar que o autor-narrador também se utiliza, assim como os missionários norte-americanos, dos fundamentos da moral cristã, enquanto instrumento do saber verdadeiro, para justificar a ação dos missionários entre os indígenas. Portanto as "verdades" da fé cristã são apresentadas na obra como parte da epistemologia imperialista norte-americana.

Fica evidente na narrativa, a partir da crítica pós-colonial e do pensamento decolonial, a afirmação e a sustentação de uma epistemologia que tenta silenciar as experiências e os conhecimentos dos povos Wai-wai, configurando, assim, o 
que se convencionou chamar de violência epistêmica e injustiça cognitiva, características mais marcantes do colonialismo na modernidade. Como estratégia persuasiva, a tessitura textual é construída numa lógica que tenta desviar o olhar do leitor para lógica da dominação e da superioridade epistêmica norte-americana. A religião cristã (evangélica), como ideologia, é um recurso utilizado para legitimar um conhecimento "universal" e concebido como verdadeiro, justificado na ação catequética dos missionários.

É possível, portanto, uma leitura decolonial dessa obra, uma vez que ela pode se tornar um símbolo da violência sistêmica do imperialismo americano contra os povos indígenas da Amazônia, o que se dá, no texto discurso escrito, através da construção de um sujeito deformador da estética e da moral adotados como padrão, segundo as orientações religiosas norte-americanas. Em contraposição, é possível também verificar, na própria narrativa, que o valor de verdade, assim como os recursos utilizados pelos missionários para disseminação e afirmação de seus conhecimentos e ideologias entre os Wai-wai, eram confrontados quando na relação direta com o lugar de enunciação indígena.

Portanto identificar as estratégias persuasivas utilizadas pelo autor-narrador na obra "O Pajé de Cristo" é fundamental, sobretudo porque ajuda desvelar o discurso imperialista norte-americano, engendrado pelos missionários evangélicos. 0 resultado deste estudo tem sido a necessidade de reinterpretação e de reescrita das narrativas sobre os povos indígenas da Amazônia como resposta ao colonizador.

\section{REFERÊNCIAS}

BALLESTRIN, L. América Latina e o giro decolonial. Revista Brasileira de Ciência Política, Brasília, n. 11, p. 89-117, maio/ago. 2013.

BRAGA, M. L. S. Produção de linguagem e ideologia. São Paulo: Cortez, 1980.

DEMO, P. Metodologia do conhecimento científico. São Paulo: Atlas, 2000.

DOWDY, H. E. O pajé de Cristo: uma história do amor de Deus operando milagres nas selvas da Amazônia. Tradução de Fausto Camargo César. New York: Harper \&Row, 1963; São Paulo: Sepal, 1997. Título original: Christ’switchdoctor.

FERREIRA, M. K. L. A educação escolar indígena: um diagnóstico crítico da situação no Brasil. In: FERREIRA, M. K. L.; LOPES DA SILVA, A. (Org.). Práticas pedagógicas na escola indígena. São Paulo: Globo, 2001. 
FIORIN, J. L. Linguagem e ideologia. São Paulo: Ática, 1998.

FOCK, N. Waiwai: religion and Society of Amazonian tribe. Copenhagen: The National Museum, 1963.

FRIKEL, P. Dez anos de aculturação Tiriyó. Mudanças e Problemas (1960-1970). Boletim MPEG, Belém, PA, Publicações Avulsas, n. 16, 1971.

HOWARD, C. A domesticação das mercadorias: estratégias Waiwai. In.: ALBERT, B.; RAMOS, A. R. (Org.). Pacificando os brancos: cosmologias do contato no Norte-Amazônico. São Paulo: UNESP/Imprensa Oficial do Estado, 2001.

LAS CASAS, F. B. de. O paraíso destruído: a sangrenta história da conquista da América Espanhola. Porto Alegre: L\&PM, 2008.

MIGNOLO, W. Desafios decoloniais hoje. Epistemologias do Sul, Foz do Iguaçu, PR, v. 1, n. 1, p. 12-32, 2017

. La idea de América Latina. La herida colonial y la opción decolonial. Barcelona: Gedisa, 2007.

Histórias globais/projetos locais. Colonialidade, saberes subalternos e pensamento limiar. Belo Horizonte: Editora UFMG, 2003.

OLIVEIRA, L. V. de. O cristianismo evangélico entre os Waiwai: alteridade e transformações entre as décadas de 1950 e 1980. Rio de Janeiro: UFRJ/Museu Nacional/PPGAS, 2010.

QUIJANO, A. Colonialidad del poder y clasificación social. In: CASTRO GÓMEZ, S.; GROSFOGUEL, R. (Org.). El giro decolonial: reflexiones para una diversidad epistémica más allá del capitalismo global. Bogotá: Siglo del Hombre Editores, 2007.

. Colonialidade do poder, eurocentrismo e América Latina. In: LANDER E. (Org.). A colonialidade do saber: eurocentrismo e ciencias sociais. Perspectivas latino-americanas. Buenos Aires, Argentina: CLACSO, 2005. Colección Sur Sur.

SANTOS, B. de S. Para além do pensamento abissal: das linhas globais a uma ecologia de saberes. Novos Estudos CEBRAP, São Paulo, n.79, p.71-94, nov. 2007.

WALSH, C. Pensamiento crítico y matriz (de)colonial. Reflexiones latinoamericanas. Quito, Equador: Ediciones Abya-Yala, 2005. p. 13-35. 


\section{Sobre os autores:}

Raimundo Nonato de Pádua Câncio: Doutor em Educação pela Universidade Federal do Pará, na Linha Educação, Cultura e Sociedade - PPGED/UFPA; Mestre em Educação pela UEPA. Professor do Curso de Pedagogia da Universidade Federal do Tocantins (UFT). Pesquisa na área da Educação Escolar Indígena, Pós-Colonialismo, decolonialidade e educação na América Latina. Está vinculado ao Grupo de Pesquisa "José Veríssimo e o Pensamento Educacional Latino-Americano" (PPGED/ UFPA).E-mail: nonato.cancio@uft.edu.br

Sônia Maria da Silva Araújo: Estágio Pós-Doutoral no Centro de Estudos Sociais (CES). Doutorado e mestrado em Educação pela Universidade de São Paulo (USP). Graduação em Pedagogia pela Universidade Federal do Pará (UFPA). É coordenadora do Programa de Pós-Graduação em Educação da UFPA. Coordena o grupo de pesquisa "José Veríssimo e o Pensamento Educacional Latino-Americano". É pesquisadora do Grupo de Pesquisa Discriminação, Preconceito, Estigma: minorias étnicas e religiosas, cultura e educação da Universidade de São Paulo (FEUSP) e do Grupo Epistemologias alternativas, movimentos sociais e educação. E-mail: ecosufpa@hotmail.com

Recebido em 1ㅇ de maio de 2018

Aprovado para publicação em 1ㅇ de agosto de 2018 
